\title{
MTHFR polymorphisms, dietary folate intake and breast cancer risk in Chinese women
}

\author{
Chang-Ming Gao ${ }^{1}$, Jin-Hai Tang ${ }^{1}$, Hai-Xia Cao ${ }^{1}$, Jian-Hua Ding ${ }^{1}$, Jian-Zhong Wu ${ }^{1}$, Jie Wang ${ }^{1}$, Yan-Ting Liu ${ }^{1}$, \\ Su-Ping $\mathrm{Li}^{1}$, Ping Su${ }^{1}$, Keitaro Matsuo ${ }^{2}$, Toshiro Takezaki ${ }^{3}$ and Kazuo Tajima ${ }^{2}$
}

To evaluate the relationship between dietary folate intake and genetic polymorphisms of 5,10-methylenetetrahydrofolate reductase (MTHFR) with reference to breast cancer risk, we conducted a case-control study with 669 cases and 682 population-based controls in the Jiangsu Province of China. MTHFR C677T and A1298C genotypes were identified using PCR-RFLP (restrictrion fragment length polymorphism) methods. Dietary folate intake was assessed using an 83-item food frequency questionnaire. Odds ratios (ORs) were estimated with an unconditional logistic model. The frequencies of MTHFR C677T $C / C, C / T$ and $\mathrm{T} / \mathrm{T}$ genotypes were $32.37,48.88$ and $18.75 \%$ in cases and $37.66,48.24$ and $14.10 \%$ in controls, respectively. The difference in distribution was significant $\left(\chi^{2}=6.616, P=0.037\right)$, the $T / T$ genotype being associated with an elevated OR (adjusted for age, menopausal status, body mass index (BMI), income, work intensity and status of smoking and drinking) for breast cancer $(1.62,95 \%$ confidence interval $(95 \% \mathrm{Cl}): 1.14-2.30)$. The frequencies of MTHFR A1298C A/A, $A / C$ and $C / C$ were $71.47,27.08$ and $1.44 \%$ in cases and $68.11,30.13$ and $1.76 \%$ in controls, respectively, with no significant differences being found $\left(\chi^{2}=1.716, P=0.424\right)$. A significant inverse relationship was observed between folate intake and breast cancer risk. Compared with the lowest tertile of folate intake, the adjusted OR for breast cancer in the top tertile was 0.70 (95\% Cl: 0.53-0.92). However, no significant interaction was observed between folate intake and the MTHFR C677T polymorphism. Among individuals with the MTHFR A1298C A/A genotype, adjusted ORs for breast cancer were 0.89 $(0.62-1.27)$ and $1.69(1.20-2.36)$ for the second to the third tertile of folate intake compared with the highest folate intake group (tread test, $P=0.0008$ ). The findings of this study suggest that $M T H F R$ genetic polymorphisms and dietary intake of folate may modify susceptibility to breast cancer.

Journal of Human Genetics (2009) 54, 414-418; doi:10.1038/jhg.2009.57; published online 26 June 2009

Keywords: breast cancer; folate; genetic polymorphisms; methylenetetrahydrofolate reductase; susceptibility

\section{INTRODUCTION}

Folate has an important role in DNA methylation, synthesis and repair, and there is epidemiological evidence indicating that low intake may increase the risk for neoplasia, including breast cancer. ${ }^{1,2}$ The mechanisms linking folate deficiency to cancer development could include uracil misincorporation, increased DNA strand breaks, aberrations in DNA methylation and disruption of DNA repair. ${ }^{3,4}$

The 5,10-methylenetetrahydrofolate reductase (MTHFR) is a key enzyme in folate metabolism, irreversibly catalyzing the 5,10-methylenetetrahydrofolate reaction to 5-methyltetrahydrofolate, the primary circulatory form of folate and a carbon donor for remethylation of homocysteine to methionine. The latter is the precursor for the universal methyl donor, $S$-adenosylmethionine. Folate that is not converted through this pathway enters another pathway that leads to purine and thymidylate synthesis. Two polymorphisms in the MTHFR gene that affect the efficiency of folate metabolism have been described (MTHFR $677 \mathrm{C}>\mathrm{T}$ transition in exon 4 and MTHFR $1298 \mathrm{~A}>\mathrm{C}$ transversion in exon 7). ${ }^{5}$ The MTHFR 677 TT genotype results in $30 \%$ enzyme activity in vitro compared with the CC wildtype ${ }^{6}$ whereas the MTHFR 1298 CC genotype has been found to have $60 \%$ of the AA wild-type enzyme activity in vitro. ${ }^{7,8}$ These low-activity genotypes seem to be associated with reduced risk for a variety of cancers, such as acute lymphocytic leukemia, lung, gastric and colorectal cancers. ${ }^{9,10}$ A number of studies have evaluated the association between the MTHFR genotype and breast cancer, but the results have been inconsistent. ${ }^{11-15}$

Our previous studies ${ }^{16-20}$ have shown relationships between genetic polymorphisms of MTHFR and susceptibility to stomach, esophageal and colorectal cancers. To evaluate the relationship between dietary folate intake and genetic polymorphisms of MTHFR with reference to breast cancer risk, we conducted this case-control study in Jiangsu Province, China.

${ }^{1}$ Division of Epidemiology, Jiangsu Province Institute of Cancer Research, Nanjing, China; ${ }^{2}$ Division of Epidemiology and Prevention, Aichi Cancer Center Research Institute, Nagoya, Japan and ${ }^{3}$ Department of International Island and Community Medicine, Kagoshima University Graduate School of Medical and Dental Sciences, 8-35-1 Sakuragaoka, Kagoshima, Japan

Correspondence: Dr C-M Gao, Division of Epidemiology, Jiangsu Provincial Institute of Cancer Research, 42 Baiziting, Nanjing 210009 , China. E-mail: gaocm888@126.com

Received 19 January 2009; revised 1 May 2009; accepted 25 May 2009; published online 26 June 2009 


\section{MATERIALS AND METHODS}

\section{Participants}

We recruited breast cancer cases using data of the Cancer Registries in Taixing, Wuxi, Jintan and Huian cities of the Jiangsu Province of China, and also recruited cases who visited the Jiangsu Province Cancer Hospital from these cities from June 2004 to December 2007. All cases were histopathologically diagnosed as having a primary breast cancer. Physicians at the hospital asked eligible cases to participate in our study, and doctors or nurses interviewed the participants and collected blood samples from a peripheral vein after obtaining informed consent. Population-based controls were selected from healthy residents in 11 villages or towns of Taixing, Wuxi, Jintan and Huian cities. Doctors of the public health centers randomly selected one or two controls for each case, after matching for ethnicity and age within 2 years using the records of residents at the local governmental office, and then asked eligible residents for their participation. Interviews were conducted and blood samples were collected as for the cancer cases. A total of 669 cases and 682 controls completed the interview, and of these 624 and 624, respectively, donated blood. A few patients and residents refused, but the rates for blood sampling were $93.3 \%$ for cases and $91.5 \%$ for controls. The ethics committee of the Jiangsu Province Institute of Cancer Research approved this study.

\section{Data and biological sample collection}

All participants completed an in-person interview that used a structured questionnaire. Dietary intakes were assessed using an 83-item food frequency questionnaire, capturing $90 \%$ of food intake and covering nutrients constituting up to $90 \%$ of the nutrient intake in urban and rural areas of the Jiangsu province. ${ }^{21}$ Each participant was asked about the frequency of a specific food that was eaten, followed by a question on the amount typically consumed. Dietary intakes of folate were calculated according to the consumption of foods, with Standard Food Composition Tables for China. ${ }^{22}$

\section{DNA extraction and genotyping}

Whole blood was collected into EDTA (ethylenediaminetetraacetic acid)-coated tubes and centrifuged for $15 \mathrm{~min}$, and the buffy coat layer was isolated. Genomic DNA was extracted from $200 \mu \mathrm{l}$ of buffy coat using a Qiagen QIAamp DNA Blood Mini Kit (Qiagen, Valencia, CA, USA). MTHFR C677T and A1298C mutations were detected after PCR amplification with corresponding primers as detailed in our previous studies. ${ }^{17-20}$ The restriction enzyme Hinf was used to distinguish the $677(\mathrm{C} \rightarrow \mathrm{T})$ polymorphism. The primers for PCR were $5^{\prime}$-TGAAGGAGAAG-GTGTCTGCGGGA- $3^{\prime}$ and $5^{\prime}$-AGGACGGTGC GGTG-AGAGTG-3'. The PCR product was subjected to Hinf I restriction enzyme digestion, and samples were then analyzed by electrophoresis in $3 \%$ agarose gels stained with ethidium bromide. There were three genotypes of MTHFR C677T, namely C/C (198 bp), C/T (198/175 bp) and T/T (175bp). The restriction enzyme $M b o \alpha$ was used to distinguish the $1298(\mathrm{~A} \rightarrow \mathrm{C})$ polymorphism. The primers for PCR were $5^{\prime}$-CTTTGGGGAGCTGAAGGACTACTAC-3' and 5'-CACTTTGTGACCATTCCGGTTTG-3'. The PCR product was subjected to $M b o \alpha$ restriction enzyme digestion, and the samples were then analyzed by electrophoresis in $4 \%$ agarose gels stained with ethidium bromide. There were three genotypes of MTHFR A1298C, namely A/A (56 bp), A/C (56/84 bp) and $\mathrm{C} / \mathrm{C}(84 \mathrm{bp})$

\section{Data analysis}

Odds ratios (ORs) were used to measure the association of breast cancer risk with the MTHFR genotype and intakes of folate. Unconditional logistic regressions from the statistical package SAS were used to obtain maximum likelihood estimates of the ORs and their 95\% confidence intervals, ${ }^{15}$ after adjusting for age, BMI, menopausal status, work intensity and status of smoking and drinking. Age and BMI were included as continuous variables throughout the study. Tertile distributions of dietary intake of folate among controls were used to categorize the variables. The probability of the HardyWeinberg equilibrium was assessed by $\chi^{2}$-test.

\section{RESULTS}

The baseline characteristics of cases and controls are summarized in Table 1. There were no significant differences between cases and controls in terms of age, BMI and menopausal status. However, significant differences were found for income per month, work intensity, smoking status and alcohol drinking status. Cases also had a lower intake of folate than controls.

Data for associations between MTHFR genotypes, folate intake and breast cancer risk are presented in Table 2. The frequencies of MTHFR C677T C/C, C/T and T/T genotypes were $32.37,48.88$ and $18.75 \%$ in cases and $37.66,48.24$ and $14.10 \%$ in controls, respectively, the difference in distribution being significantly different $\left(\chi^{2}=6.616\right.$, $P=0.037)$. The $\mathrm{T} / \mathrm{T}$ genotype was associated with an elevated $\mathrm{OR}$ (adjusted for age, menopausal status, BMI, income, work intensity and status of smoking and drinking) for breast cancer (1.62, 95\% CI: 1.14-2.30). The frequencies of MTHFR A1298C A/A, A/C and C/C

Table 1 Comparison of cases and controls by selected descriptive characteristics

\begin{tabular}{|c|c|c|c|c|}
\hline Subject characteristics & $\begin{array}{l}\text { Cases } \\
(\mathrm{n}=669)\end{array}$ & $\begin{array}{l}\text { Controls } \\
(\mathrm{n}=682)\end{array}$ & $\chi^{2}$ & P-value \\
\hline \multicolumn{5}{|l|}{ Age (years) } \\
\hline$<40$ & $76(11.36)$ & $87(12.76)$ & 0.978 & 0.807 \\
\hline $40-49$ & $226(33.78)$ & $229(33.58)$ & & \\
\hline $50-59$ & 227 (33.93) & $234(34.31)$ & & \\
\hline$\geqslant 60$ & $140(20.93)$ & $132(19.35)$ & & \\
\hline \multicolumn{5}{|l|}{ Menopausal status } \\
\hline Postmenopausal & $360(53.81)$ & $390(57.18)$ & 1.555 & 0.212 \\
\hline Premenopausal & 309 (46.19) & $292(42.72)$ & & \\
\hline \multicolumn{5}{|l|}{$B M I$} \\
\hline$\leqslant 22.9$ & $326(48.73)$ & $350(51.32)$ & 0.950 & 0.622 \\
\hline $23-29.9$ & $321(47.98)$ & $312(45.75)$ & & \\
\hline$\geqslant 30$ & $22(3.29)$ & $20(2.93)$ & & \\
\hline \multicolumn{5}{|l|}{ Income/month } \\
\hline Lower & $286(42.75)$ & $362(53.08)$ & 19.769 & 0.001 \\
\hline Middle & $216(32.29)$ & $208(30.50)$ & & \\
\hline High & $167(24.96)$ & $112(16.42)$ & & \\
\hline \multicolumn{5}{|l|}{ Work intensity } \\
\hline Heavy physical force work & $30(4.55)$ & $15(2.24)$ & 17.596 & 0.001 \\
\hline $\begin{array}{l}\text { Light and heavy } \\
\text { physical force work }\end{array}$ & $312(47.34)$ & $377(56.35)$ & & \\
\hline Light physical force work & 224 (33.99) & $211(31.54)$ & & \\
\hline Headwork & $91(13.81)$ & $62(9.27)$ & & \\
\hline Unknown & $2(0.30)$ & $4(0.60)$ & & \\
\hline \multicolumn{5}{|l|}{ Smoking status } \\
\hline Never & $653(97.61)$ & 677 (99.27) & 8.066 & 0.024 \\
\hline Ever & $10(1.49)$ & $1(0.15)$ & & \\
\hline Current & $6(0.90)$ & $4(0.59)$ & & \\
\hline \multicolumn{5}{|l|}{ Alcohol drinking status } \\
\hline Never & $637(95.22)$ & 662 (97.07) & 7.497 & 0.024 \\
\hline Ever & $14(2.09)$ & $3(0.44)$ & & \\
\hline Current & $18(2.69)$ & $17(2.49)$ & & \\
\hline
\end{tabular}

Intake of folate $(\mu \mathrm{g} /$ day $) \quad 263.00 \pm 137.38285 .12 \pm 149.61$

0.0047

Abbreviation: BMI, body mass index. 
Table 2 Adjusted odds ratios (ORs) and 95\% confidence intervals (Cls) for breast cancer with respect to MTHFR polymorphisms and dietary folate intake

\begin{tabular}{|c|c|c|c|c|}
\hline & Cases (\%) & Controls (\%) & $O R^{\mathrm{a}}(C l)$ & $O R^{b}(C l)$ \\
\hline \multicolumn{5}{|c|}{ MTHFR C677T } \\
\hline $\mathrm{C} / \mathrm{C}$ & $202(32.37)$ & 235 (37.66) & 1.00 & 1.00 \\
\hline $\mathrm{C} / \mathrm{T}$ & $305(48.88)$ & $301(48.24)$ & $1.20(0.93-1.54)$ & $1.20(0.93-1.55)$ \\
\hline $\mathrm{T} / \mathrm{T}$ & $117(18.75)$ & $88(14.10)$ & $1.62(1.15-2.28)$ & $1.62(1.14-2.30)$ \\
\hline
\end{tabular}

MTHFR A1298C

$\begin{array}{lcccc}\mathrm{A} / \mathrm{A} & 446(71.47) & 425(68.11) & 1.00 & 1.00 \\ \mathrm{~A} / \mathrm{C} & 169(27.08) & 188(30.13) & 0.86(0.67-1.10) & 0.91(0.82-1.13) \\ \mathrm{C} / \mathrm{C} & 9(1.44) & 11(1.76) & 0.83(0.34-2.04) & 0.78(0.31-1.99) \\ \mathrm{A} / \mathrm{C}+\mathrm{C} / \mathrm{C} & 178(28.53) & 199(31.89) & 0.86(0.67-1.10) & 0.90(0.70-1.15)\end{array}$

Folate intake ( $\mu \mathrm{g} /$ day)

$\leqslant 199.08282(42.15) \quad 227(33.28) \quad 1.00 \quad 1.00$

199.09- $197(29.45) \quad 228(33.43) \quad 0.71(0.55-0.92) \quad 0.70(0.53-0.91)$

315.10

$\geqslant 315.11 \quad 190(28.40) \quad 227(33.28) \quad 0.69(0.53-0.90) \quad 0.70(0.53-0.92)$

Abbreviations: BMI, body mass index; MTHFR, 5,10-methylenetetrahydrofolate reductase. aORs were adjusted for age and menopausal status.

bORs were adjusted for age, BMI, income, menopausal status, work intensity and status of smoking and drinking.

Table 3 Interaction between MTHFR C677T and A1298C genotypes and the odds ratios (ORs) for breast cancer

\begin{tabular}{llrrcc}
\hline C677T & A1298C & Cases $(n)$ & Controls $(n)$ & $O R^{\mathrm{a}}(95 \% \mathrm{Cl})$ & $O^{\mathrm{b}}(95 \% \mathrm{Cl})$ \\
\hline $\mathrm{C} / \mathrm{C}$ & $\mathrm{A} / \mathrm{A}$ & 134 & 139 & 1.00 & 1.00 \\
& $\mathrm{~A} / \mathrm{C}$ & 65 & 90 & $0.77(0.51-1.15)$ & $0.82(0.54-1.24)$ \\
& $\mathrm{C} / \mathrm{C}$ & 3 & 6 & $0.53(0.12-2.24)$ & $0.61(0.14-2.63)$ \\
$\mathrm{C} / \mathrm{T}$ & $\mathrm{A} / \mathrm{A}$ & 313 & 209 & $1.08(0.80-1.47)$ & $1.12(0.82-1.53)$ \\
& $\mathrm{A} / \mathrm{C}$ & 86 & 87 & $1.04(0.41-1.53)$ & $1.13(0.76-1.68)$ \\
& $\mathrm{C} / \mathrm{C}$ & 6 & 5 & $1.59(0.46-5.46)$ & $1.50(0.41-5.50)$ \\
$\mathrm{T} / \mathrm{T}$ & $\mathrm{A} / \mathrm{A}$ & 99 & 77 & $1.38(0.94-2.03)$ & $1.41(0.95-2.09)$ \\
& A/C & 18 & 11 & $1.90(0.85-4.26)$ & $1.97(0.86-4.50)$
\end{tabular}

Abbreviations: BMI, body mass index; Cl, confidence interval; MTHFR, 5,10-methylenetetrahydrofolate reductase.

aORs were adjusted by age and menopausal status.

bORs were adjusted by age, BMI, income, menopausal status, work intensity and status of smoking and drinking.

were $71.47,27.08$ and $1.44 \%$ in cases and $68.11,30.13$ and $1.76 \%$ in controls, respectively, with no significant differences being found $\left(\chi^{2}=1.716, P=0.424\right)$. Among the controls, the distributions of MTHFR genotypes did not differ from the predicted distribution under the Hardy-Weinberg equilibrium $\left(P>0.05, \chi^{2}=0.287\right.$ for the C677T polymorphism and $\chi^{2}=3.638$ for the $A 1298 C$ polymorphism). A significant inverse relationship was observed between folate intake and breast cancer risk. Compared with the lowest tertile of folate intake, the adjusted OR for breast cancer in the top tertile was 0.70 (95\% CI: 0.53-0.92).

Results of associated effect on breast cancer risk between MTHFR677 and 1298 genotypes are described in Table 3. When MTHFR677 C/C with 1298 A/A genotypes were considered as the reference group, MTHFR677 C/C with $1298 \mathrm{C} / \mathrm{C}$ genotypes showed the lowest adjusted OR $(0.61 ; 95 \%$ CI: $0.14-2.63)$. On the other hand, MTHFR677 T/T with 1298 A/C genotypes showed the highest adjusted
OR (1.97; 95\% CI: $0.86-4.50)$, but these ORs were not statistically significant.

The data were further analyzed to examine the combined effects of MTHFR677 and 1298 genotypes and folate intake on risk for breast cancer (Table 4). Among $677 \mathrm{C} / \mathrm{C}, \mathrm{C} / \mathrm{T}$ and $1298 \mathrm{~A} / \mathrm{A}$ genotypes, the ORs were increased along with a decrease in folate intake, the trend being statistically significant for $677 \mathrm{C} / \mathrm{T}(P=0.0062)$ and $1298 \mathrm{~A} / \mathrm{A}$ genotypes $(P=0.0008)$. Compared with the group having the $677 \mathrm{C} / \mathrm{C}$ genotype and high folate intake, the $677 \mathrm{~T} / \mathrm{T}$ genotype and high or low folate intake groups all had elevated ORs for breast cancer. The 677 T/T genotype with high folate intake had the highest OR $(2.41,95 \%$ CI: 1.22-4.74) for breast cancer. Among individuals with $1298 \mathrm{~A} / \mathrm{A}$ and $677 \mathrm{C} / \mathrm{T}$ genotypes, ORs for breast cancer were increased along with a decrease in folate intake, the adjusted ORs for breast cancer being 0.97 (0.53-1.77), $1.06(0.57-1.97)$ and 2.19 (1.25-3.83) for the highest to the third tertile of folate intake, respectively (trend test, $P=0.0005$ ).

\section{DISCUSSION}

In this study of associations of two common polymorphisms in MTHFR (C677T and A1298C), a gene that has a central role in folate metabolism, we found the MTHFR 677 TT genotype to significantly increase the risk of breast cancer, whereas dietary intake of folate showed an inverse association with the risk of breast cancer. We also found that lower folate intake was particularly linked to increased risk of breast cancer among individuals with MTHFR 1298A/A and $677 \mathrm{C} / \mathrm{C}$ or $677 \mathrm{C} / \mathrm{T}$ genotype.

Previous studies have generated inconsistent findings on the MTHFR polymorphism and folate intake associations with breast cancer risk. MTHFR 677TT and 1298CC genotypes cause decreased enzyme activity, ${ }^{6-8}$ and some studies have indicated that the MTHFR 677TT genotype confers greater risk of breast cancer, especially in women in the premenopausal stage. ${ }^{13,14,23-27}$ Many meta-analysis studies have also supported this conclusion. ${ }^{11,15}$ On the other hand, no association between MTHFR genotypes and the risk of breast cancer was noted in other studies ${ }^{28-32}$ and two meta-analyses. ${ }^{12,33}$ The reasons for these inconsistent results are not clear, but clearly variation with ethnicity and environment could contribute to differences in influence on the development of breast cancer.

It has been shown consistently that the pathophysiological consequences of MTHFR genetic variants, especially the C677T polymorphism, are significantly affected by demographic and environmental factors, such as folate status, age, smoking and alcohol intake, all parameters that may additionally alter the fine equilibrium of one carbon metabolism. ${ }^{10,34}$ In particular, the phenotypic effects of C677T and A1298C polymorphisms are affected by the folate status. ${ }^{3,6,35}$ It has been suggested that the stability of the polymorphic enzyme is significantly modified by folate levels. Under conditions of high intracellular folate, the folate molecule may be able to hold the variant MTHFR protein in the appropriate and fully functional threedimensional form, thus stabilizing the thermolabile structure and counteracting reduction in enzyme activity. ${ }^{35}$

Folate is an essential nutrient that supports nucleotide synthesis and biological methylation reactions. A number of epidemiological studies have suggested an inverse association between dietary intake and blood levels of folate and breast cancer risk..$^{34,36,37}$ Several previous studies have also indicated a gene-nutrient interaction between the MTHFR C677T polymorphism and dietary folate intake in breast carcinogenesis, in which the 677TT genotype was associated with an elevated risk when dietary folate intake was low; ${ }^{14,24,38}$ however, a meta-analysis ${ }^{12}$ concluded that there was no evidence of an interaction between folate intake and the MTHFR genotype on breast cancer risk. 
Table 4 Joint associations of the MTHFR genotype and folate intake with breast cancer risk

\begin{tabular}{|c|c|c|c|c|c|c|c|}
\hline \multirow{2}{*}{$\begin{array}{l}\text { MTHFR } \\
\text { Genotype }\end{array}$} & \multicolumn{2}{|c|}{ Folate intake T1 (high) } & \multicolumn{2}{|c|}{ T2 } & \multicolumn{2}{|c|}{ T3 (low) } & \multirow[b]{2}{*}{$\mathrm{P}_{\text {for trend }}$} \\
\hline & Case/cont. & $O R^{a}(C l)$ & Case/cont. & $O R^{a}(C l)$ & Case/cont. & $O R^{\mathrm{a}}(C l)$ & \\
\hline $\mathrm{C} / \mathrm{C}$ & $58 / 80$ & 1.00 & $64 / 82$ & $1.01(0.60-1.68)$ & $82 / 73$ & $1.54(0.95-2.49)$ & 0.0593 \\
\hline $\mathrm{C} / \mathrm{T}$ & $81 / 99$ & $1.18(0.73-1.91)$ & $86 / 102$ & $1.18(0.72-1.91)$ & $138 / 100$ & $1.96(1.26-3.04)$ & 0.0062 \\
\hline$T / T$ & $40 / 26$ & $2.41(1.22-4.74)$ & $33 / 27$ & $1.66(0.86-3.19)$ & 44/35 & $1.87(1.02-3.43)$ & 0.5660 \\
\hline \multicolumn{8}{|l|}{ A1298C } \\
\hline $\mathrm{A} / \mathrm{A}$ & 123/139 & 1.00 & 120/151 & $0.89(0.62-1.27)$ & 203/135 & $1.69(1.20-2.36)$ & 0.0008 \\
\hline $\mathrm{A} / \mathrm{C}+\mathrm{C} / \mathrm{C}$ & $54 / 66$ & $1.10(0.69-1.75)$ & $63 / 60$ & $1.25(0.79-1.98)$ & $61 / 73$ & $0.96(0.62-1.48)$ & 0.9609 \\
\hline \multicolumn{8}{|l|}{ A1298C-A/A } \\
\hline C677T-C/C & $36 / 45$ & 1.00 & $41 / 52$ & $0.89(0.47-1.71)$ & $57 / 42$ & $1.84(0.98-3.46)$ & 0.0693 \\
\hline \multicolumn{8}{|l|}{$A 1298 C-A / C+C / C$} \\
\hline C677T-C/C & $20 / 35$ & 1.00 & $23 / 30$ & $1.06(0.42-2.65)$ & $25 / 31$ & $1.37(0.61-3.10)$ & 0.3785 \\
\hline $\mathrm{C} 677 \mathrm{~T}-\mathrm{C} / \mathrm{T}+\mathrm{T} / \mathrm{T}$ & $34 / 31$ & $1.88(0.84-4.22)$ & $40 / 30$ & $1.89(0.85-4.20)$ & $36 / 42$ & $1.32(0.60-2.87)$ & 0.4301 \\
\hline
\end{tabular}

Abbreviations: BMI, body mass index; $\mathrm{Cl}$, confidence interval; cont, control; MTHFR, 5,10-methylenetetrahydrofolate reductase; OR, odds ratio.

aORs were adjusted for age, BMI, income, menopausal status, work intensity and status of smoking and drinking.

In this study, we found the total amount of dietary intake of folate to be inversely associated with risk of breast cancer, that is, the ORs were increasing along with decreasing folate intake among MTHFR677 C/C and $\mathrm{C} / \mathrm{T}$ genotypes. We also noted that groups with the MTHFR677 $\mathrm{T} / \mathrm{T}$ genotype showed elevated ORs or breast cancer regardless of high or low folate intake (Table 4). The protective effect of folate in breast carcinogenesis might be dependent on MTHFR genotypes. In a nested case-control study, Ericson et al. ${ }^{39}$ found that high folate intake increases the risk of breast cancer among women with MTHFR677CT/TT-1298AA, whereas it tends to decrease the risk in compound heterozygous (677CT-1298AC) women. Our similar findings imply that folate might be involved in the development of breast cancer, but its mechanism is incomprehensive from the present evidence.

Several studies have indicated links between the MTHFR 677TT genotype and decreased plasma folate, increased plasma homocysteine and a low DNA uracil content. ${ }^{40,41}$ The accumulation of uracil in DNA can induce mutagenic lesions, including chromosome breaks. Chou et al. ${ }^{42}$ reported that elevated plasma homocysteine levels may be significantly linked to increased risk of breast cancer (adjusted OR: 2.89, 95\% CI: $1.70-4.92$ for the highest tertile compared with the lowest tertile). Therefore, MTHFR C677T may modulate the risk of breast carcinogenesis. However, the data are not all consistent. Several studies have in fact reported that the MTHFR1298CC genotype is associated with a reduced risk of developing breast cancer. ${ }^{24,43}$ Chou et al. ${ }^{35}$ observed a significantly reduced risk associated with the compound low-activity MTHFR genotypes and the reduction was stronger among women with low plasma folate levels. They argued that the reduced risk might perhaps be due to increasing 5, 10methylene-THF levels for DNA synthesis. In this study, we observed an increased risk of breast cancer associated with low folate intake in individuals with $1298 \mathrm{~A} / \mathrm{A}$ genotypes (Table 4). Chen et al. ${ }^{24}$ and Ergul et al. ${ }^{27}$ reported earlier that T677T/A1298A showed an increased risk for breast cancer. In the Shanghai breast cancer study, elevated ORs were associated with folate intake in the 1298AA group $(P=0.006){ }^{38}$ These findings may be attributed to the $1298 \mathrm{C}$ allele having limited functionality or high linkage with the $677 \mathrm{C}$ low-risk allele. ${ }^{24}$

Two reviews indicated that folate may have dual modulatory effects on the development and progression of cancer depending on the intervention timing and dose. ${ }^{34,44}$ High folate intake (mainly from folic acid supplementation) could indeed be harmful. StolzenbergSolomon et al. ${ }^{45}$ reported that although food folate intake was not significantly related to breast cancer risk, total folate intake, mainly from folic acid supplementation, significantly increased breast cancer risk by $32 \%$. We observed an increased risk of breast cancer associated with the $677 \mathrm{TT}$ genotype among those with high folate intake (OR: 2.41, 95\% CI: 1.22-4.74). It is likely that the less active MTHFR 677 enzyme and high folate intake cause an elevated folate status. Therefore, the role of folate metabolism in breast carcinogenesis is highly complex.

Finally, some limitations require discussion. The main results obtained in this study could also be affected by sources of selection bias that commonly emerged in case-control studies. There are 40 ethnic subgroups in the Jiangsu population of China, although the Han nationality accounts for $99.82 \%$ of the total population, and variation of ethnic subgroups in the participants of this study was not regulated. However, the allele and genotype frequencies of the two MTHFR loci among our controls seemed consistent with those derived from the Hardy-Weinberg equilibrium. In our study, the T-allele frequency in MTHFR C677T is 0.38, and the C-allele frequency in MTHFR A1298C is 0.17 in the control group. The statistical powers were $95.3 \%(\mathrm{OR}=1.5)$ and $100 \%(\mathrm{OR}=2.0)$ for C677T, and 80.8\% $(\mathrm{OR}=1.5)$ and $99.9 \%(\mathrm{OR}=2)$ for A1298C. The genotyping method of PCR-RFLP (restrictrion fragment length polymorphism) and the lack of $\alpha$-error adjustment for multiple factors analysis might generate some potential limitations, and therefore the interpretation of this finding needs caution. 
In summary, this study showed a relevance of folate metabolism to breast cancer susceptibility among the Chinese female population of the Jiangsu province. Thus, the results add support to the literature pointing to a role of folate metabolism in carcinogenesis of the breast. However, further studies are needed for confirmation.

\section{ACKNOWLEDGEMENTS}

This study was supported in part by a Grant-in-Aid for International Scientific Research, Special Cancer Research from the Ministry of Education, Science, Sports, Culture and Technology of Japan, No. 11137311, and the Major Research Projects Foundation for Society Development from the Department of Science and Technology of Jiangsu Province of China, No. BS2006006. The authors thank the staff of the Public Health Centers of Taixing, Wuxi, Jintan and Huian cities for their assistance in data collection.

1 Kim, Y. I. Folate and carcinogenesis: evidence, mechanisms, and implications. J. Nutr. Biochem. 10, 66-88 (1999).

2 Mason, J. B. \& Choi, S. W. Folate and carcinogenesis: developing a unifying hypothesis. Adv. Enzyme Regul. 40, 127-141 (2000).

3 Bailey, L. B. \& Gregory, J. F. III Polymorphisms of methylenetetrahydrofolate reductase and other enzymes: metabolic significance, risks and impact on folate requirement. J. Nutr. 129, 919-922 (1999).

4 Choi, S. W. \& Mason, J. B. Folate and carcinogenesis: an integrated scheme. J. Nutr. 130, 129-132 (2000).

5 Fodinger, M., Horl, W. H. \& Sunder-Plassmann, G. Molecular biology of 5,10-methylenetetrahydrofolate reductase. J. Nephrol. 13, 20-33 (2000).

6 Frosst, P., Blom, H. J., Milos, R., Goyette, P., Sheppard, C. A., Matthews, R. G. et al. A candidate genetic risk factor for vascular disease: a common mutation in methylenetetrahydrofolate reductase. Nat. Genet. 10, 111-113 (1995).

7 van der Put, N. M., Gabreels, F., Stevens, E. M., Smeitink, J. A., Trijbels, F. J., Eskes, T. $\mathrm{K}$. et al. A second common mutation in the methylenetetrahydrofolate reductase gene: an additional risk factor for neural-tube defects? Am. J. Hum. Genet. 62, 1044-1051 (1998).

8 Weisberg, I., Tran, P., Christensen, B., Sibani, S. \& Rozen, R. A second genetic polymorphism in methylenetetrahydrofolate reductase (MTHFR) associated with decreased enzyme activity. Mol. Genet. Metab. 64, 169-172 (1998).

9 Thomas, P. \& Fenech, M. Methylenetetrahydrofolate reductase, common polymorphisms, and relation to disease. Vitam. Horm. 79, 375-392 (2008).

10 Boccia, S., Hung, R., Ricciardi, G., Gianfagna, F., Ebert, M. P., Fang, J. Y. et al. Metaand pooled analyses of the methylenetetrahydrofolate reductase C677T and A1298C polymorphisms and gastric cancer risk: a huge-GSEC review. Am. J. Epidemiol. 167, 505-516 (2008).

11 Langsenlehner, T., Renner, W., Yazdani-Biuki, B. \& Langsenlehner, U. Methylenetetrahydrofolate reductase (MTHFR) and breast cancer risk: a nested-case-control study and a pooled meta-analysis. Breast Cancer Res. Treat. 107, 459-460 (2008).

12 Lewis, S. J., Harbord, R. M., Harris, R. \& Smith, G. D. Meta-analyses of observational and genetic association studies of folate intakes or levels and breast cancer risk. J. Nat/ Cancer Inst. 98, 1607-1622 (2006).

13 Zintzaras, E. Methylenetetrahydrofolate reductase gene and susceptibility to breast cancer: a meta-analysis. Clin. Genet. 69, 327-336 (2006).

14 Suzuki, T., Matsuo, K., Hirose, K., Hiraki, A., Kawase, T., Watanabe, M. et al. Onecarbon metabolism-related gene polymorphisms and risk of breast cancer. Carcinogenesis 29, 356-362 (2008).

15 Macis, D., Maisonneuve, P., Johansson, H., Bonanni, B., Botteri, E., lodice, S. et al. Methylenetetrahydrofolate reductase (MTHFR) and breast cancer risk: a nested-casecontrol study and a pooled meta-analysis. Breast Cancer Res. Treat. 106, 263-271 (2007).

16 Cao, H. X., Gao, C. M., Takezaki, T., Wu, J. Z., Ding, J. H., Liu, Y. T. et al. Genetic polymorphisms of methylenetetrahydrofolate reductase and susceptibility to colorectal cancer. Asian Pac. J. Cancer Prev. 9, 203-208 (2008).

17 Gao, C., Wu, J., Ding, J., Liu, Y., Zang, Y., Li, S. et al. [Polymorphisms of methylenetetrahydrofolate reductase C677T and the risk of stomach cancer]. Zhonghua Liu Xing Bing Xue Za Zhi. 23, 289-292 (2002).

18 Gao, C. M., Wu, J. Z., Liu, Y. T., Ding, J. H., Li, S. P., Su, P. et al. [Interactions between lifestyle, methylanetetrahydrofolate reductase gene and polymorphisms in thymidylate synthase gene with risk of stomach cancer]. Zhonghua Liu Xing Bing Xue Za Zhi. 24, 599-603 (2003).

19 Gao, C. M., Takezaki, T., Wu, J. Z., Liu, Y. T., Ding, J. H., Li, S. P. et al. Polymorphisms in thymidylate synthase and methylenetetrahydrofolate reductase genes and the susceptibility to esophageal and stomach cancer with smoking. Asian Pac. J. Cancer Prev. 5, 133-138 (2004)

20 Gao, C. M., Toshiro, T., Wu, J. Z., Cao, H. X., Liu, Y. T., Ding, J. H. et al. [A case-control study on the polymorphisms of methylenetetrahydrofolate reductase $1298 \mathrm{~A} \rightarrow \mathrm{C}$ and susceptibility of esophageal cancer]. Zhonghua Liu Xing Bing Xue Za Zhi. 25, 341-345 (2004).

21 Wang, Y. M., Mo, B. Q., Takezaki, T., Imaeda, N., Kimura, M., Wang, X. R. et al. Geographical variation in nutrient intake between urban and rural areas of Jiangsu province, China and development of a semi-quantitative food frequency questionnaire for middle-aged inhabitants. J. Epidemiol. 13, 80-89 (2003).

22 Yang, Y. X. China Food Composition 2004, 1ts edn. (Peking University Medical Press, Peking, 2005).

23 Semenza, J. C., Delfino, R. J., Ziogas, A. \& Anton-Culver, H. Breast cancer risk and methylenetetrahydrofolate reductase polymorphism. Breast Cancer Res. Treat. 77, 217-223 (2003).

24 Chen, J., Gammon, M. D., Chan, W., Palomeque, C., Wetmur, J. G., Kabat, G. C. et al. One-carbon metabolism, MTHFR polymorphisms, and risk of breast cancer. Cancer Res. 65, 1606-1614 (2005).

25 Stevens, V. L., McCullough, M. L., Pavluck, A. L., Talbot, J. T., Feigelson, H. S., Thun, M. J. et al. Association of polymorphisms in one-carbon metabolism genes and postmenopausal breast cancer incidence. Cancer Epidemiol. Biomarkers Prev. 16, 1140-1147 (2007).

26 Deligezer, U., Akisik, E. E. \& Dalay, N. Homozygosity at the C677T of the MTHFR gene is associated with increased breast cancer risk in the Turkish population. In Vivo. 19, 889-893 (2005).

27 Ergul, E., Sazci, A., Utkan, Z. \& Canturk, N. Z. Polymorphisms in the MTHFR gene are associated with breast cancer. Tumour Biol. 24, 286-290 (2003).

28 Justenhoven, C., Hamann, U., Pierl, C. B., Rabstein, S., Pesch, B., Harth, V. et al. Onecarbon metabolism and breast cancer risk: no association of MTHFR, MTR, and TYMS polymorphisms in the GENICA study from Germany. Cancer Epidemiol. Biomarkers Prev. 14, 3015-3018 (2005).

29 Grieu, F., Powell, B., Beilby, J. \& lacopetta, B. Methylenetetrahydrofolate reductase and thymidylate synthase polymorphisms are not associated with breast cancer risk or phenotype. Anticancer Res. 24, 3215-3219 (2004).

30 Kotsopoulos, J., Zhang, W. W., Zhang, S., McCready, D., Trudeau, M., Zhang, P. et al. Polymorphisms in folate metabolizing enzymes and transport proteins and the risk of breast cancer. Breast Cancer Res. Treat. 112, 585-593 (2008).

31 Reljic, A., Simundic, A. M., Topic, E., Nikolac, N., Justinic, D. \& Stefanovic, M. The methylenetetrahydrofolate reductase (MTHFR) C677T polymorphism and cancer risk: the Croatian case-control study. Clin. Biochem. 40, 981-985 (2007).

32 Hekim, N., Ergen, A., Yaylim, I., Yilmaz, H., Zeybek, U., Ozturk, O. et al. No association between methylenetetrahydrofolate reductase $\mathrm{C677T}$ polymorphism and breast cancer. Cell Biochem. Funct. 25, 115-117 (2007).

33 Lissowska, J., Gaudet, M. M., Brinton, L. A., Chanock, S. J., Peplonska, B., Welch, R. et al. Genetic polymorphisms in the one-carbon metabolism pathway and breast cancer risk: a population-based case-control study and meta-analyses. Int. J. Cancer 120, 2696-2703 (2007).

$34 \mathrm{Kim}$, Y. I. Does a high folate intake increase the risk of breast cancer? Nutr. Rev. 64, 468-475 (2006).

35 Chou, Y. C., Wu, M. H., Yu, J. C., Lee, M. S., Yang, T., Shih, H. L. et al. Genetic polymorphisms of the methylenetetrahydrofolate reductase gene, plasma folate levels and breast cancer susceptibility: a case-control study in Taiwan. Carcinogenesis 27, 2295-2300 (2006)

36 Brekelmans, C. T. Risk factors and risk reduction of breast and ovarian cancer. Curr. Opin. Obstet. Gynecol. 15, 63-68 (2003).

37 Zhang, S. M. Role of vitamins in the risk, prevention, and treatment of breast cancer. Curr. Opin. Obstet. Gynecol. 16, 19-25 (2004).

38 Shrubsole, M. J., Gao, Y. T., Cai, Q., Shu, X. O., Dai, Q., Hebert, J. R. et al. MTHFR polymorphisms, dietary folate intake, and breast cancer risk: results from the Shanghai Breast Cancer Study. Cancer Epidemiol. Biomarkers Prev. 13, 190-196 (2004).

39 Ericson, U., Sonestedt, E., Ivarsson, M. I., Gullberg, B., Carlson, J., Olsson, H. et al. Folate intake, methylenetetrahydrofolate reductase polymorphisms, and breast cancer risk in women from the Malmö Diet and Cancer cohort. Cancer Epidemiol. Biomarkers Prev. 18, 1101-1110 (2009).

40 Yang, Q. H., Botto, L. D., Gallagher, M., Friedman, J. M., Sanders, C. L., Koontz, D. et al. Prevalence and effects of gene-gene and gene-nutrient interactions on serum folate and serum total homocysteine concentrations in the United States: findings from the third National Health and Nutrition Examination Survey DNA Bank. Am. J. Clin. Nutr. 88, 232-246 (2008).

41 DeVos, L., Chanson, A., Liu, Z., Ciappio, E. D., Parnell, L. D., Mason, J. B. et al. Associations between single nucleotide polymorphisms in folate uptake and metabolizing genes with blood folate, homocysteine, and DNA uracil concentrations. Am. J. Clin. Nutr. 88, 1149-1158 (2008).

42 Chou, Y. C., Lee, M. S., Wu, M. H., Shih, H. L., Yang, T., Yu, C. P. et al. Plasma homocysteine as a metabolic risk factor for breast cancer: findings from a case-control study in Taiwan. Breast Cancer Res. Treat. 101, 199-205 (2007).

43 Sharp, L., Little, J., Schofield, A. C., Pavlidou, E., Cotton, S. C., Miedzybrodzka, Z. et al. Folate and breast cancer: the role of polymorphisms in methylenetetrahydrofolate reductase (MTHFR). Cancer Lett. 181, 65-71 (2002).

44 Ulrich, C. M. Folate and cancer prevention: a closer look at a complex picture. Am. J. Clin. Nutr. 86, 271-273 (2007)

45 Stolzenberg-Solomon, R. Z., Chang, S. C., Leitzmann, M. F., Johnson, K. A., Johnson, C., Buys, S. S. et al. Folate intake, alcohol use, and postmenopausal breast cancer risk in the Prostate, Lung, Colorectal, and Ovarian Cancer Screening Trial. Am. J. Clin. Nutr. 83, 895-904 (2006). 